\title{
PERFORMANCE AUTORAL E IMAGINÁRIO DE UM TERRITÓRIO LITERÁRIO NA OBRA DE ALDYR GARCIA SCHLEE
}

\section{PERFORMANCE AUTORAL Y IMAGINÁRIO DE UN TERRITÓRIO LITERÁRIO EM LA OBRA DE ALDYR GARCIA SCHLEE}

Cátia Dias Goulart ${ }^{9}$

RESUMO: Considerando um amplo repertório da obra ficcional do escritor Aldyr Garcia Schlee, desenvolvo neste artigo uma reflexão sobre a performance autoral assumida por seus narradores e a respeito da relação dos mesmos com a criação de uma região cultural entre o sul do Brasil e o Uruguai. Recorro, no campo teórico, a Paul Ricoeur (1996), pois tanto sua concepção de imaginário enquanto relação criadora do universo do real, como sua compreensão acerca das relações entre memória pessoal e coletiva (2000), oferecem pautas significativas para o exercício hermenêutico. Os aportes dos críticos argentinos Ricardo Káliman (1993) e Zulma Palermo (1994), no tocante a suas visões acerca de região cultural como um construto simbólico que implica as noções de espaço, tempo e perspectiva, também me subsidiam no diálogo com a obra do escritor fronteiriço. $O$ caminho percorrido nesse processo de leitura contribui para um maior conhecimento da produção ficcional de Schlee, obra que promove continua reflexão sobre os mundos que o escritor co-habita, entre eles, o da arte.

Palavras-chave: Schlee; metaficção; literatura de fronteira; literatura da comarca pampiana.

RESUMEN: A partir de un amplio repertorio de la obra ficcional del escritor Aldyr Garcia Schlee desarrollo en este artículo una reflexión sobre la performance autoral de sus narradores y la relación de los

9 Doutora em Letras, Teoria da Literatura, na Pontifícia Universidade Católica do Rio Grande do Sul-PUC/RS. Estágio de Doutorado Sanduíche na Université Sorbonne, Paris IV, com bolsa CAPES. Professora da Universidade Federal do Pampa-UNIPAMPA. 


\section{6 | Cátia Dias Goulart}

mismos con la creación de una región cultural entre el sur de Brasil y el Uruguay. Recurro, en el campo teórico, a Paul Ricoeur (1996), una vez que tanto su concepción de imaginario en cuanto relación creadora del universo de lo real, como su comprensión acerca de las relaciones entre memoria personal y colectiva (2000), ofrecen coordinadas significativas para el ejercicio hermenéutico. Los aportes de los críticos argentinos Ricardo Káliman (1993) y Zulma Palermo (1994) en lo que se refiere a sus visiones acerca de región cultural como un constructo simbólico que conlleva las nociones de espacio, tiempo y perspectiva, también subsidian mi diálogo con la obra del escritor fronterizo. El camino recorrido en ese proceso de lectura contribuye para un más profundo conocimiento de la producción ficcional de Schlee, obra que promueve continua reflexión acerca de los mundos que el escritor co-habita, entre ellos, el del arte.

Palabras-clave: Schlee; metaficción; literatura de frontera; literatura de la comarca pampeana.

Tal qual o reposicionamento de imaginários feito pelo artista plástico Torres García, em sua tela Norte-Sur $(1936)^{10}$, o escritor fronteiriço Aldyr Garcia Schlee ${ }^{11}$ problematiza, a partir de sua produção ficcional, uma máxima que se construiu lentamente ao longo da Modernidade e ainda cala no imaginário de muitos de nós ao redor do mundo. Se, para o pintor uruguaio, a orientação que ele propõe é necessária "... porque en realidad nuestro norte es el sur", para o escritor

${ }^{10}$ A tela Norte-Sur (1936), de Joaquín Torres García é composta pelo seguinte texto verbal que acompanha o Mapa: "He dicho Escuela del Sur; porque en realidad, nuestro norte es el Sur. No debe haber norte, para nosotros, sino por oposición a nuestro Sur. Por eso ahora ponemos el mapa al revés, y entonces ya tenemos justa idea de nuestra posición, y no como quieren en el resto del mundo. La punta de América, desde ahora, prolongándose, señala insistentemente el Sur, nuestro norte”. Joaquín Torres García. Universalismo Constructivo, Bs. As.: Poseidón, 1941. Disponível em: <http://www.torresgarcia.org.uy>.

${ }^{11}$ Nascido em Jaguarão, fronteira com Rio Branco, no Uruguay, no ano de 1934, de onde saiu aos 17 anos para trabalhar como desenhista gráfico e caricaturista em jornais de Pelotas, Rio de Janeiro e Porto Alegre, Schlee vivia nas últimas décadas de sua vida em Capão do Leão, pequeno município localizado entre sua cidade natal e Pelotas. 

na obra de Aldyr Garcia Schlee | 67

brasileiro, pensar "JAGUARÃO... E O RESTO DO MUNDO" (1988) é um modo de situar sua perspectiva criativa e criadora do mundo em que vivemos.

Parece-me importante destacar que a dissimulação do lugar epistêmico que sempre norteou a cartografia ${ }^{12}$, questão com a qual a tela de Torres García evidentemente dialoga, pode ser relacionada à perspectiva de universalidade com que o campo da crítica literária, ao longo do processo da Modernidade, situou - e muitas vezes ainda hoje hierarquiza - a produção ficcional de escritores ao redor do mundo. As teorias críticas e fundamentações de ordem estéticas conduziram por longo tempo a uma perspectiva universalista em relação às obras literárias. Os critérios avaliativos associados a modelos dos quais partiam/partem para a elaboração de tais critérios incidiram fortemente em hierarquias, exclusões e formação de cânones.

Nesse sentido, como bem apontam as reflexões de Zulma Palermo (1994), a falsa dicotomia entre cânones locais, regionais e universais, apesar de bastante discutida é, ainda e com frequência, dissimulada, e predomina em nosso imaginário não só no âmbito de escolhas de textos ficcionais, mas, também, nos fundamentos epistemológicos de nossas pesquisas. Ainda parafraseando a pensadora argentina, talvez o valor maior de obras tidas como locais (nacionais/regionais) não resida tanto no potencial de reconhecimento universal, mas antes na capacidade de legitimidade que têm junto a suas próprias comunidades de origem, questão para a qual o olhar crítico precisa estar atento.

${ }^{12}$ A cumplicidade entre a geografia e a epistemologia evidencia-se já desde o Mapa-Múndi medieval. $\mathrm{O}$ mapa cristão conhecido como $\mathrm{T}$ em $\mathrm{O}$, traçado por Isidoro Sevilha, no século IX, confere à Ásia uma posição privilegiada, colocando-a na parte superior da representação terrestre, uma vez que nela estaria o Paraíso, em Jerusalém. Essa perspectiva dos tempos medievais, com a "descoberta de novas terras", a América, a partir de fins do século $\mathrm{XV}$, foi ampliada para uma quarta parte de representação do planeta e a Europa passou à parte superior e central da nova representação. Esse novo imaginário ocidental traçado no Orbis Universalis Terrarum, de Abraham Ortelius, tornou-se paradigmático até a atualidade. Ver: MIGNOLO, W. "El ocidentalismo y La 'americanidad' de América”. In: _______. La Idea de América Latina - la herida colonial y la opción decolonial. Barcelona: Gedisa, 2007, p. 48-58. 


\section{8 | Cátia Dias Goulart}

Considerando esses aspectos, estimo que os dois artistas aqui mencionados, ao marcarem o posicionamento de seus imaginários, chamam a atenção para a necessidade do leitor atentar para os loci de enunciação implicados em toda criação humana.

Assim, é importante considerar que a posição do sentir, do olhar e da voz, sobretudo em produções culturais simbólicas, sempre carrega consigo memórias múltiplas que se inter-relacionam e se refazem enquanto memórias individuais e coletivas, marcadas pelo transcurso de tempos e espaços, como bem nos esclarece e orienta Paul Ricoeur, especialmente, em "Memória Pessoal, Memória Coletiva", capítulo de uma de suas últimas obras A memória, a história o esquecimento (2000).

Associada a esse entendimento está a concepção de imaginário, como uma relação criadora do universo do real, também apontada por Ricoeur (1996). Afinal, é por esse viés, conforme o hermeneuta francês, que a concepção do real é indissociável da interpretação que os seres humanos lhe atribuem. Portanto, o processo de significação imagética do real constitui-se tanto por uma dimensão cognitiva, de ordem semântica, quanto afetiva, razão pela qual adquire sua configuração nos símbolos. Seguindo ainda o pensamento hermenêutico de Ricoeur, entendo "que o símbolo hesita entre o bios e o logos" porque nele radica o discurso da vida (RICOEUR, 1996, p. 71).

Assim, é necessário atentar para as posições geoculturais - Sul, Cone Sul, Sul do Brasil -, marcadas nas obras dos dois artistas aqui enfocados, não só porque nelas estão implicadas múltiplas memórias que coexistem e se inter-relacionam em suas produções, mas, sobretudo, porque chamam a atenção para o que deveria ser óbvio para todos nós: a criação sempre se dá a partir de um lugar; é, portanto, local.

Evidentemente, tal compreensão não significa desconsiderar a pretensão potencialmente universal de seus trabalhos, mas é sim, uma reafirmação da diferença, como aponta Palermo em seus estudos acerca da literatura de Salta. Creio que reconhecer tais posições - dos artistas e de críticos - e suas consequentes implicações, viabilizam uma visão plural e enriquecedora do mundo em que vivemos, sem nos deixar cair em "regionalismos", "pós-regionalismos" e nem, tampouco, em novos "universalismos", presentes na retórica da globalização.

$\mathrm{Na}$ metade dos anos trinta, Torres García, ao inverter o convencional mapa das Américas desestabiliza um paradigma que, gestado a partir de fins do século XV, está fossilizado no imaginário social. Com esse gesto criativo, o pintor uruguaio abre outras possibilidades de entendimento da cartografia que tradicionalmente tem nos representado. 
Afinal, mais do que uma inversão da referência de uma ordem geográfica, seu traçado simbólico põe em evidência a relação entre perspectiva e representação, e, por esse viés, o pintor uruguaio chama a atenção não só para as implicações de ordem política e epistemológica presentes em toda representação, sejam elas no campo das ditas ciências, como a cartografia, ou das artes, mas, sobretudo, para que se assuma essa relação.

O desenhista, escritor, tradutor e pesquisador Garcia Schlee, no início da década de sessenta ${ }^{13}$, atento à proposta de Torres García, também chama a atenção para o fato de que pensar a partir do que lhe é próprio - por sua condição, especialmente, de ficcionista, sureño e fronteiriço - é criar a partir desses espaços. É nessa perspectiva que Jaguarão, enquanto território imaginário schleeriano, emerge de um olhar descolonizador sobre a cidade homônima. É no contraponto de histórias que dividem a região, situação decorrente não só de políticas centralizadoras dos governos nacionais, mas também dos poderes locais, que se desenvolve o território ficcional do escritor. Assumindo essa perspectiva, ele opta, ao longo de todo seu processo criativo, por pensar "na contramão", posição que não seria possível "se não abordasse a contrapelo aquilo que usualmente nos identifica”. (SCHLEE, 2004, p. 49)

Para isso, o escritor tensiona múltiplos discursos e promove outras possibilidades de se entender, imaginar e criar o território que habita. Evidentemente o verbo habitar, utilizado por mim para localizar a obra do escritor, não se restringe a uma referência geográfica, mas sim, sobretudo, ao modo como Schlee gesta sua posição enquanto artista que cria a partir de um lugar. Afinal, viver-escrever em uma região do Cone Sul, a partir de fronteiras, implica, como vemos pelo conjunto da produção de Schlee,

13 As duas primeiras obras publicadas por Schlee, resultado de duas premiações consecutivas no concurso Nestlé de Literatura Brasileira, foram Contos de sempre (1983) e Uma Terra Só (1984). No entanto, sua terceira obra lançada, Linha divisória (1988), integra duas coletâneas de contos: Jaguarão e o resto do mundo, premiada com menção honrosa em concurso promovido, em 1964, pela Divisão de Cultura do Estado do Rio Grande do Sul; e Jaguarão Universo, também premiada com menção honrosa, com o prêmio José Lins do Rego, promovido pela editora José Olympio, do Rio de Janeiro, em 1968. Ambas as coletâneas, ainda não publicadas, acabaram sendo integradas à terceira obra publicada pelo escritor, razão pela qual destaco a criação de uma perspectiva na obra do escritor que se gesta a partir da década de sessenta. 


\section{0 | Cátia Dias Goulart}

situar-se em espaços específicos, mas ainda assim móveis, que se constituem em contínuo diálogo entre os mundos que o escritor cohabita, entre eles, o da arte.

A produção ficcional do escritor, artista plástico, jornalista, tradutor e professor Aldyr Garcia Schlee é composta por um número expressivo e variado de obras. No campo da ficção: Contos de sempre (1983); Uma Terra Só (1984); Linha divisória (1988); El dia en que el Papa fue a Melo (1991); Cuentos de fútbol (1997); Contos de verdades (2000); Os limites do impossivel - contos gardelianos (2009); Don Frutos (2010); Contos da vida difícil (2013), Memórias de o que já não será (2014), Fitas de cinema (2015) e O Outro lado - noveleta pueblera (2018). Além da criação ficcional, Schlee traduziu dois clássicos da literatura argentina: Facundo - civilização e barbárie, de Domingo Faustino Sarmiento (1996) e Don Segundo Sombra, de Ricardo Güiraldes (2011). Da literatura uruguaia traduziu narrativas de Eduardo Acevedo Díaz, organizando a antologia Pátria uruguaia, (1997) e, em parceria com o também escritor Sergio Faraco, a antologia de contos Para sempre Uruguai (1990). No campo da autotradução, destacamse os livros Contos de futebol (1998) e O dia em que o Papa foi a Melo (1999), ambas originalmente lançadas em espanhol e, mais recentemente, Los limites de lo imposible - cuentos gardelianos (2018), traduzido por Rosario Peyrou.

No âmbito das artes gráficas e plásticas, Schlee, além de ter atuado profissionalmente como planejador gráfico em jornais nos estados do Rio de Janeiro e do Rio Grande do Sul, desde sua adolescência desenvolveu uma significativa produção de desenhos e caricaturas que se bem tiveram algum espaço de visibilidade por ocasião da exposição The Beautiful Game: O Reino da Camisa Canarinho (2014), no Museu de Direitos Humanos do Mercosul, graças à pesquisa e curadoria de José Francisco Neves, esta é uma faceta do artista que ainda carece de espaço de divulgação e de estudo específico $^{14}$.

Com seu último trabalho, resultado de uma longa pesquisa, e de sua experiência criativa no campo da literatura de sua região cultural, bem

\footnotetext{
14 O desenhista tem sido reconhecido desde 1953, sobretudo por ser o criador do uniforme oficial da seleção brasileira de futebol, principal motivo pelo qual o artista foi homenageado nessa exposição que contou com a presença de obras de mais dez artistas plásticos. Catálogo da exposição: ALVES, J. F. The Beautiful Game: $\bigcirc$ Reino da Camisa canarinho. Porto Alegre: 2014.
} 

na obra de Aldyr Garcia Schlee | 71

como de seu encantamento pela etimologia das palavras, Schlee deixou pronta obra que foi lançada postumamente, o Dicionário da Comarca Pampeana Sul-Rio-Grandense (2018). Assim, transgredindo continuamente as pretensas fronteiras da arte, da pesquisa e também as perspectivas nacionalistas, como bem indica já o título, que assume o trânsito entre os dois idiomas, o escritor atualiza o próprio conceito de comarca pampiana.

Essa obra é resultado de "um trabalho de toda uma vida" (SCHLEE, 2019, s/n) do escritor lidando com as palavras. Ao percorrer as páginas do dicionário, podemos imaginar o olhar do menino atento que pelas ruas de Jaguarão e Rio Branco já “colecionava palavras" e, sobretudo, reconhecer o escritor que seguiu até seus últimos dias buscando entender e recriar para si e para nós, seus leitores, a região cultural da comarca pampiana, bem como as inter-relações desse lugar com outras localidades no mundo.

A perspectiva indicada no título do dicionário ganha vida no tratamento de cada verbete, mas já pode ser acompanhada, pelo leitor, a partir dos paratextos que introduzem o dicionário. É nesse espaço que Schlee situa a obra na história da região e em sua história de leitorescritor. Em um desses textos introdutórios ele nos lembra que por mais de dois séculos desenvolveu-se no extremo sul do Brasil, mais precisamente na metade sul do Rio Grande do Sul, uma forma muito singular e característica de cultura: a cultura pampeana - própria do Pampa, região de pastagens da América do Sul que ocupa a planície costeira e interiorana do Rio da Prata (e de seus formadores: Paraná e Uruguai), desde a província de Buenos Aires até a parte meridional do Rio Grande do Sul, incluindo toda a República Oriental do Uruguai. Mas, sobretudo, o escritor-leitor revela suas principais fontes de pesquisa e, com elas, um fecundo elemento de integração-construção dessa região cultural: a literatura produzida em parte da Argentina, do Uruguai e sul do Brasil.

Buscando marcar sua perspectiva de trabalho e orientar o leitor, o escritor-pesquisador, na parte intitulada - A LEITURA DO DICIONÁRIO - I -, informa que:

[...] não basta, nem bastou escolher e recolher este ou aquele vocábulo na linguagem literária das obras que constituem o corpus da pesquisa: é e foi preciso escolhê-los e recolhê-los de um contexto próprio e característico de determinado conteúdo lexical. (SCHLEE, 2019, s/n). 
Como busco exemplificar brevemente com essa citação, Schlee situa seu trabalho realizado com o campo lexical no contexto de um sistema literário e cultural de sua própria região cultural. É interessante, contudo, destacar que se no dicionário Schlee tem como fonte principal um conjunto ficcional da literatura gauchesca transnacional, como pode ser visualizado na referência a obras de escritores argentinos, uruguaios e brasileiros, a produção ficcional do escritor, de modo predominante, desenvolve-se por outro caminho.

A opção estética desse escritor fronteiriço, em certa continuidade com a linha aberta pela literatura gauchesca, privilegia personagens que estão à margem do poder. Mas diferentemente dessa vertente fundacional e fecunda de um sistema transacional da literatura da comarca pampiana, em que as personagens estão vinculadas ao campo, a narrativa schleeriana volta-se predominantemente para o meio urbano. Escolha essa que amplia significativamente as inscrições sociais desse espaço cultural, na obra do escritor.

Ainda que Schlee, em sua produção ficcional, tenha um relevante repertório de narrativas vinculadas ao campo e à formação política do território $^{15}$, vertente que lida com a história política, com os oscilantes conflitos e acordos de fundação da região, o escritor investe na possibilidade de ressignificar a história a partir do tensionamento de múltiplas perspectivas implicadas na construção do lugar, as quais foram obliteradas pelos discursos do poder ao longo da história da região.

Por esse viés, Schlee dialoga e atua na revitalização da literatura gauchesca, como pode ser exemplificado com os contos "A viúva de

15 A vertente vinculada à literatura gauchesca é a mais frequentemente estudada entre a produção ficcional do escritor, conforme podemos acompanhar na primeira dissertação de mestrado dedicada à obra do autor, bem como a tese de doutorado de Fabiane Resende, publicizadas, respectivamente, $\quad\langle$ http://repositorio.furg.br/> e $\langle$ http://www.lume.ufrgs.br/>. Também em uma mesma perspectiva comparatista de leitura destaco as dissertações de Silvia Niederauer Xavier, intitulada Gaúchos e castelhanos - sem linha divisória (a imagem do castelhano na literatura sul-rio-grandense), e a de Angelise Fagundes da Silva, Aldyr Schlee e o entrelugar: a questão da fronteira em Uma terra só, ambas desenvolvidas no programa de pós-graduação da Universidade Federal de Santa Maria (UFSM) Ver: 〈http://cascavel.cpd.ufsm.br/〉. 

na obra de Aldyr Garcia Schlee | 73

Quinteros" ou "Don Sejanes", de Contos de Sempre, entre outros. ${ }^{16}$ Também relacionadas a essa linha criativa, mas em diálogo mais direto com as estratégias do novo discurso ficcional histórico na América Latina, em que personagens da histórica cultural e política são problematizadas, o escritor desenvolveu narrativas mais longas como Don Frutos e Os Limites do impossivel - contos gardelianos ${ }^{17}$.

Porém, ciente de que "Una región no es nunca sólo una circunscripción en el continuo del espacio. Es siempre también una circunscripción en el continuo del tiempo. Una región es, por lo tanto, siempre un período (como, en realidad, un período histórico, es también, siempre, una región.)" (KÁLIMAN, 1993, p. 2); o território literário de Schlee tem seu ritmo temporal centrado no século XX, momento de urbanização da região e de forte reconfiguração de imaginários da Modernidade em todo o mundo.

O território simbólico da obra schleeriana mobiliza o leitor a considerar várias referências desse processo de transformação na região: o trânsito fluvial internacional pelo rio Jaguarão (1904), a construção da ponte internacional Barão de Mauá (1927-1930), o movimento da linha férrea (1932). Além dessas vias de ligação com Montevidéu e Buenos Aires, também os requintados cabarés, os prostíbulos, os cinemas, as ruas e os casarões das pequenas cidades, como Jaguarão, Rio Branco e, eventualmente, Pelotas, Rio Grande e Melo, integrados ao universo criativo do escritor, conferem o compasso temporal predominante em seus enunciados.

Esse espaço simbólico, de um pretenso progresso nas primeiras décadas do século XX, em um mundo que se modernizava, adquire significados mais profundos pela vivência de personagens como ex-peões,

${ }^{16}$ Dedico-me ao a refletir sobre a literatura gauchesca como vertente fundacional de uma literatura de fronteira da comarca pampiana e suas relações com a crítica literária em: GOULART, C. "A criação de uma tradição crítica na América Latina e o imaginário da literatura transfronteriça no sul do Brasil”. Caderno de Letras, n. 26, jan-jun, pp. 93 $123,2016$.

${ }^{17}$ Com relação a essa obra ver: GOULART, C. "Cuentos gardelianos: una biografia de la ausencia”. Revista Les Ateliers Du Sal, n.7, pp.132-141, 2015. Disponível em: <https://lesateliersdusalfr.wordpress.com/numerosprecedents/deuxiemeepoque/Numero-7/articles-numero-7>. 


\section{4 | Cátia Dias Goulart}

changadores, desempregados, jogadores de futebol, donas de casa, empregadas domésticas, prostitutas, proxenetas, cafetinas, entre outros, e ainda pela presença, por vezes tangencial e, em outras, central, de uma diversidade étnica que emerge em suas narrativas. Algumas de origem palestina, "os turcos", franceses, alemães, poloneses, "as polacas", ingleses, decorrentes de imigrações permanentes e/ou de passagens voluntárias ou forçadas para a região, devido às transformações por que passava "o resto do mundo". Casos em que, ainda que poucas tenham protagonismo na obra do escritor, a presença de tais personagens potencializa uma reflexão sobre a diversidade étnica e cultural no jogo da memória como inscrição das formações sociais da região.

É no descompasso entre o desenvolvimento e o progresso sinalizado pelo processo de modernização da região e a continuidade da miséria, da exclusão e dos conflitos de valores sociais, que o escritor situa predominantemente suas personagens e cria seu espaço simbólico. A partir desse amplo núcleo, sua obra diversifica-se, voltando-se, por vezes, para questões mais locais, como, por exemplo, um significativo conjunto de textos relativos a memórias cotidianas da região. Mas também e em outros tantos textos, o escritor desenvolve temas que sinalizam continuidades e semelhanças com ocorrências em outros lugares no mundo. Nesses casos, o expressivo conjunto ficcional schleeriano, relacionado às narrativas fílmicas ou à prostituição são muito reveladoras.

No âmbito das relações entre cinema e sua criação ficcional, o escritor desenvolve caminhos discursivos associados às conquistas da linguagem do cinema, como por exemplo em "Ida e volta", da obra Linha Divisória. Em determinadas narrativas, sugere a relação entre suas personagens e as fílmicas, como no conto "O Barco das Ilusões", de Uma Terra Só. E, em outras, inclusive, apropria-se do argumento narrativo ou de um dos motivos que integram a narrativa fílmica e o adapta à sua região cultural, como é o caso de "Sedotta e abbandonata", de Fitas de cinema.

$\mathrm{Na}$ base desse conjunto de relações promovidas pelo escritor, está o fato de que, afinal, o processo de modernização por que passa a região tem consequências e tratamentos semelhantes de exclusão, marginalização e ocultamento de histórias e memórias que também ocorreram/ocorrem em outras localidades. Por isso, os argumentos dos filmes, quando integrados em diferentes graus de intensidade à narrativa ficcional schleeriana, mobilizam leituras entrecruzadas e viabilizam uma abertura 

na obra de Aldyr Garcia Schlee | 75

maior, para que se leia a região, tanto no campo da história social quanto literária, em sua inter-relação com o mundo em que vivemos.

Para entendermos como o escritor assume sua perspectiva criativa é necessário, portanto, não só considerar o diálogo subversivo - "a contrapelo" - que ele mantém no campo dos enunciados em sua produção ficcional, mas também estarmos atentos à voz narrativa que instaura cada texto que lemos. Porque se um dos princípios criativos do escritor é relativo ao campo da memória, vividas, pesquisadas, lidas, imaginadas e sugeridas em tempos e espaços específicos, o outro, é a posição criadora que assumem seus narradores na construção desse espaço simbólico. $O$ caráter metaficcional de muitos de seus textos, aqui bem pode ser exemplificado pelo narrador de "O Barco das Ilusões", um dos contos já citados anteriormente: "Não sei como contar essa história - que são duas, ou três ou tantas!...”. (SCHLEE, 1984, p. 125)

A frequente posição autoral assumida pelos narradores de Schlee, a partir de uma performance no processo da escrita dos textos e do desnudamento da natureza ficcional de suas narrativas, são estratégias criativas que se entrecruzam com seu empenho em dialogar de modo muito expressivo com a memória de uma região cultural delimitada entre a Argentina, o Uruguay e o sul do Brasil. Nesse processo, ainda é necessário considerar que recorrentes indícios e inclusão de dados de cunho autobiográfico, remissivos à vida do escritor e à sua literatura, joga com sutis afastamentos, estratégia bastante significativa na composição de seus narradores.

Nesse sentido, no conto "Ida e volta", Schlee, explorando os recursos entre as estratégias de narrar do discurso cinematográfico e da literatura, lida, como uma câmara com alternância de perspectivas, aparentemente simultâneas, entre o narrador e outra personagem. Estratégia que desencadeia uma abertura para pensarmos o quanto nossas memórias individuais estão interligadas às nossas experiências em âmbito social. Sem contudo isentar-se de seu papel: é a voz do narrador que mais uma vez remete, a partir da diegese, a experiências vitais do escritor, por seu aparente "autoexílio", por sua expressiva relação com o cinema, por sua condição de escritor que carrega consigo o exercício estético de (re)criar seu espaço simbólico: "a gente sai por aí, anda pelo mundo, vê tudo, pensa que sabe, mas não sabe e não vê mais que o próprio mundo". (SCHLEE, 1988, p. 11)

De fato, a autorrepresentação na obra de Schlee assume diferentes intensidades e matizes em cada um de seus textos e, portanto, requerem 


\section{6 | Cátia Dias Goulart}

estudos mais específicos. Cabe aqui, no entanto, já apontar que os desdobramentos dessa estratégia narrativa, tal qual a referências geoculturais presentes nos textos, orientam o leitor em seu processo interpretativo. É nesse sentido que a performance autoral, tão frequente na obra do escritor, pode ser vista como uma referência fundacional de seus textos. Tomá-la como tal é considerar essa atuação não somente a partir da seleção de dados de ordem biográfica - extratextual - dispersos ao longo da obra do escritor e de uma autoimagem criativa - contextual e intratextual - que vai se formando e reafirmando também ao longo de toda a obra do escritor, mas, sobretudo, essa autorrepresentação pode ser compreendida como uma estratégia discursiva por parte do escritor na construção de sua posição autoral. Afinal, frente a "todo um sul sem norte" e mediante uma obra que destaca constantemente os limites e insuficiências da memória e da linguagem para contar, seria incompressível um mundo sem referências. Esse princípio mobiliza as duas atitudes do escritor: situar e (re)criar o espaço implica também situar e criar quem o imagina.

Nesse processo, a ambiguidade da voz narrativa em torno de sua própria imagem acentua a natureza dupla da literatura, já que, como bem nos adverte o escritor e crítico argentino Juan Jose Saer em seu artigo "El concepto de ficción”, ao tratar das íntimas relações entre o gênero biográfico e ficcional.

La ficción no es, por lo tanto, una reivindicación de lo falso. Aun aquellas ficciones que incorporan lo falso de un modo deliberado - fuentes falsas, atribuciones falsas, confusión de datos históricos con datos imaginarios, etcétera - lo hacen no para confundir el lector, sino para señalar el carácter doble de la ficción, que mezcla, de un modo inevitable, lo empírico y lo imaginario. (SAER, 2012, p.12)

Tendo aqui destacado as múltiplas facetas do artista, observo que tive oportunidade de iniciar-me em uma delas, a de sua produção ficcional, em minha tese doutoral, desenvolvida entre os anos de 2012 $2016^{18}$. É considerando esses estudos que na primeira parte desse artigo

${ }^{18}$ GOULART, C. Imaginários do Sul: pensamento crítico de fronteira e os avessos da Modernidade na ficção de Aldyr Garcia Schlee. Cátia Dias 
busquei apresentar uma breve contextualização da obra do escritor, destacando dois de seus princípios criativos: a relação entre construção de uma região cultural e performance autoral. Agora, na segunda parte, desenvolvo mais detidamente a leitura de uma obra que nos permite compreender melhor como essa poética narrativa mobiliza o leitor a refletir sobre a outra face do progresso, tanto nessa região cultural, quanto em outras localidades no mundo.

Para isso restrinjo-me a Contos da vida difícil (2013), uma obra composta de treze contos e que tem como "apêndice" o "Trecho de filme", uma leitura criativa / recriadora do texto fílmico Sedotta e abbandonata -, do diretor Pietro Germi, uma produção ítalo-francesa de 1964. Texto que foi, posteriormente, incluído no conjunto de contos de Fitas de cinema.

Em Contos da vida difícil, há dois conjuntos de contos que, apesar de não estarem separados formalmente, podemos enquanto leitores organizar a partir das personagens que integram tais narrativas e sua relação com o universo da prostituição, eixo temático da obra. $\mathrm{O}$ primeiro conjunto é composto por protagonistas vinculadas ao tráfico de mulheres da Europa para as Américas: "Uma mulher de passada", "O que passou com Juan Carlos", "R.S.” e "Dona Rachel”. O segundo, por personagens "nascidas" na comarca pampiana, como é o caso dos contos: "Viva eu viva ela...," "La virgencita", "O sétimo mandamento", "Adoración”, "Dia 29 de fevereiro", "Mamá Burnes", "Dizem que dizem” e "A gorda Violeta".

O livro, em tela, é apresentado por dois prefácios, entremeados por duas citações: uma do jornalista e escritor Albert Londres e a outra, do filósofo Paul Ricoeur, textos que orientam um leitor atento.

O primeiro prefácio, intitulado "A difícil vida fácil", segue as funções clássicas desse gênero discursivo. Nele, o escritor oferece o contexto em que estão situadas as narrativas ficcionais dessa obra, cito: "São velhas histórias jaguarenses que todos fizemos questão de ocultar desde o início do século XX [...] - e até hoje, já vão quase cem anos". (SCHLEE, 2013, s/n) E ainda explica as razões para a criação das mesmas a partir de dois caminhos predominantes.

Goulart. 230 p. Tese (Doutorado)- Pontifícia Universidade Católica do Rio Grande do Sul. Faculdade de Letras. Programa de Pós-Graduação em Letras, Doutorado em Teoria da Literatura, 2016. Disponível em: <http://tede2.pucrs.br/tede2/handle/tede/6683>. 


\section{8 | Cátia Dias Goulart}

Por um desses caminhos, o escritor situa os lugares comuns e preconceituosos com que o tema da prostituição tem sido frequentemente tratado, questão que o próprio título do livro indicia. Logo, ele explicita, no texto, a partir de referências a atitudes sociais cotidianas, os preconceitos, prejuicios, e seus consequentes prejuízos para lidar com a questão. E critica, sobretudo, as abordagens melodramáticas e estereotipadas que, ao privilegiarem a violência e a perversidade do universo prostibulário, bem caracterizam uma sociedade conformada por suas próprias mazelas.

Em um segundo caminho, Schlee aponta significativas fontes de pesquisa para a sua criação ficcional. Destaca, assim, o livro Las rutas de Eros - la trata de Blancas en el Atlántico Sur. Argentina, Brasil y Uruguay (1880-1932), fruto da dissertação de mestrado da uruguaia Ivete Trochon (2006), como uma de suas principais fontes para o processo criativo. Ele adiciona ainda dados históricos sobre a região da fronteira, tais como a importância da circulação fluvial entre Brasil e Uruguai, a partir de 1904, a construção da Ponte Internacional Mauá, entre 1920-30, a implantação da rede ferroviária e o intenso fluxo de imigrantes para Jaguarão-Rio Branco nesse período, situando as principais vias de interlocução entre a região e a modernização que ocorria em todo o mundo ocidental do início do século XX, momento esse em que "naturalmente a cidade se encheu de mulheres, apareceram automóveis e gramofones, surgiram negócios e empregos construíram-se casas e fortunas - era farra e trabalho, trabalho e farra”. (s/n)

Assim, relacionando dados históricos e referindo-se a memórias seletivas - a dos outros e a suas -, o escritor indica outra referência para a criação de sua obra com uma epígrafe de Albert Londres: "Mirar lo que nadie quiere mirar". Provocando o leitor a ir más allá do que costumamos ir acerca desse tema, ao evocar Londres, Schlee nos mobiliza a uma outra fonte. Afinal, o repórter e poeta francês de grande prestígio nos anos vinte foi enviado pela Liga das Nações $^{19}$ para a América a fim de

${ }^{19}$ A Liga das Nações foi uma organização internacional criada em 1920 no contexto de pós-Primeira Guerra. Segundo Flávia Piovesan, o órgão "tinha como finalidade promover a cooperação, paz e segurança internacional, condenando agressões externas contra a integridade territorial e a independência política de seus membros." (PIOVESAN, 1997, 34). Nesse caminho a convenção da Liga das Nações ainda

estabelecia sanções econômicas e militares a serem impostas pela 

na obra de Aldyr Garcia Schlee | 79

investigar o centro de importação de mulheres da Europa para a América do Sul. Nesse processo, Londres, disfarçando-se e ingressando no submundo prostibulário acaba produzindo uma coletânea de ensaios ficcionais, intitulado Le chemin de Buenos Aires, no ano de 1927.

Se com essas referências Schlee indicia algumas de suas fontes de pesquisa - acadêmicas, históricas e ficcionais - acerca do tráfico de mulheres de Europa às Américas nas primeiras décadas do século XX, também chama a atenção para a natureza dupla da literatura e suas implicações no processo de leitura.

Se com o primeiro prefácio e com a epígrafe Schlee de London orienta o leitor acerca de seu processo criativo, com a segunda citação, de Paul Ricoeur, o escritor sugere ao seu leitor a concepção de memória que ele próprio adota em sua obra ficcional. Afinal, a citação do hermeneuta francês alerta:

A memória se faz de lembranças que são aceitas e outras que não são. Ao rememorar as lembranças, nós as colocamos numa ordem, selecionando-as, escolhendo-as e adotando-as, na medida em que correspondam à valorização de acontecimentos apropriados; e ignorando-as e excluindo-as, quando correspondam à necessidade de repressão de acontecimentos inapropriados. (RICOEUR, apud SCHLEE, 2013, s/n)

Por esse viés, Schlee cumpre - como um editor - o papel de situar a obra em seus contextos, deixando assim para o seu primeiro conto -

comunidade internacional aos Estados que violassem suas obrigações, o que representou uma redefinição do conceito de soberania estatal absoluta, segundo a pesquisadora. Além disso, ainda que a noção de proteção internacional dos direitos humanos não tenha adquirido aceitação pela comunidade das nações, o órgão apontou algumas previsões genéricas a respeito do Direito Internacional dos Direitos Humanos, entre eles, referências para um padrão internacional do trabalho e uma atenção para as minorias, dois aspectos que levaram a Liga das Nações a contratar o jornalista Albert Londres para a missão nas Américas. Ver: PIOVESAN, F. Direitos Humanos e o Direito Constitucional Internacional. 3ed. atual. São Paulo: Max Limonad, 1997. 
"Carnet de divertissement" (SCHLEE, 2013, p.13) - orientações mais afeitas a seu estilo de escrever prefácios, que são quase prefácios ou mais do que prefácios, sem deixar de sê-lo. Para o escritor, seus paratextos prefácios e posfácios - costumam ser espaços de criação, onde ele trata tanto do tema da obra que anuncia, quanto da relação entre arte e realidade e, em especial, de seu modo de lidar com suas memórias acerca de sua região cultural, mas frequentemente a partir de uma estratégia de linguagem que põe o texto em uma situação ambígua enquanto gênero.

É então o que Schlee faz em "Carnet de divertissement", onde anuncia que sua fonte para a criação ficcional é também outra. Recorrendo a um clichê tantas vezes utilizado pelas estratégias de criação literária do século XIX, isto é, a do livro, diário, e neste caso, de uma caderneta encontrada casualmente ou recebida, um narrador-escritor expõe sua imaginação criativa: "Esse carnet de divertissement está aqui diante de mim e me sugere os nomes em torno dos quais esta história poderia se desenvolver e se transformar num conto..." (SCHLEE, 2013, p.13).

Esta estratégia, por um lado, põe em xeque a autenticidade de sua - ou de qualquer fonte. Por outro, leva o leitor a tomar conhecimento então que na referida caderneta só há nomes, sobrenomes, datas e horários marcados em "perfeita caligrafia" entre "muitos mandamais jaguarenses" e mulheres, como nos diz o narrador em seu processo criativo. Assim, ainda que "se a mulher estava de passagem pela cidade, se os favores e as anotações que ela oferecia ao interessado eram favores pecaminosos e lúbricas as atenções - isso não se sabe -, pois não está escrito no caderno, embora tenha sido imaginado.... " (SCHLEE, 2013, p. 17). Portanto, a caderneta inventada ou recebida ${ }^{20}$, torna-se a fonte

20 Interessante é que, posteriormente à leitura da obra, tive a oportunidade de conhecer várias cadernetas desse gênero, com formato e anotações muito semelhantes ao sugerido pelo escritor, na magistral exposição "Splendeurs et misères - Images de la prostitution 1850-1910", aberta em Paris, de 22 de setembro de 2015 a 17 de janeiro de 2016, no Musée d'Orsay. A exposição reunia pinturas, esculturas, fotografias de diversos artistas que abordaram o universo prostibulário, mas também excertos de filmes pornográficos e vários outros objetos como mobílias, livros de registro policial e de agendamento de encontros, entre outros, que não só registram, mas também fomentam um imaginário em torno do que foi o cotidiano da prostituição em suas diferentes modalidades. THOMSON, 

na obra de Aldyr Garcia Schlee | 81

principal do conjunto ficcional apresentado por essa narrativa, já não mais a dissertação anunciada no primeiro prefácio.

Schlee aponta, assim, os caminhos percorridos - da memória, históricos e literários - mobilizando seu leitor a ingressar na obra, orientando-o não só em relação a natureza ficcional desse prefácio-conto, mas, sobretudo, em relação a todo o conjunto que anuncia. Ou seja, o escritor, promovendo um jogo entre os dois prefácios, um mais de caráter informativo, outro relativo ao tratamento que ele, leitor-escritor, confere às fontes - historiográficas, literárias, sejam orais ou escritas- põe em relevo, a partir da própria ficção, a natureza de sua obra. Evidentemente, o jogo prefacial associa-se ainda às duas epígrafes que entremeiam as duas narrativas, como destaquei anteriormente.

Do conjunto de Contos da vida difícil, aqui já contextualizado, destaco o conto "R.S.", porque essa breve narrativa desafia o leitor, a partir de sugestivos tópicos acerca da história da prostituição entre a Europa e as Américas em meados do século XX, e do universo da arte com a qual dialoga, em especial do cinema, bem como da problematização da (des)memória de uma região cultural, toda potencialidade de sua contística. E diria que o desafio é um convite a que o leitor atue, paradoxalmente, de modo inverso aos passos criativos do ficcionista, para desenvolver em melhores condições seu próprio texto de interpretação, ou seja, o conto indiciando seu processo de pesquisa, associações, recriação de fontes, mobiliza o leitor a assumir o conto mesmo como principal fio condutor para produção de seu texto interpretativo. Tentada pelos entrecruzamentos propostos pelas estratégias textuais, experimento um lugar de leitura, a partir do conto "R.S." e convido a outros a que também dialoguem com a obra schleeriana.

O principal núcleo narrativo desse conto apresenta Sara, uma caftina de origem polonesa - ou russa - que, como outras estrangeiras também passaram pelo histórico Cabaré de Tomasinho, na cidade de Jaguarão. Ainda que o narrador questione:

Quem poderia acreditar em Jaguarão que ela fora virgem disputada em São Francisco? Que viera com a mãe da Rússia para a França, da França para a Argentina, da Argentina para os Estados Unidos... e que tinha menos de

R. PLUDEMACHER, I. (Comp.) Splendeurs et misères - Images de la prostitution 1850-1910". Paris: M.O Flammarion, 2015. 
vinte anos ao aparecer aqui na fronteira quando mal começavam a chegar para a construção da Ponte os homens de toda laia e de todo mundo que ela haveria de atender a cada noite, cada semana, cada mês ... (SCHLEE, 2013, p. 45)

Mas, se o motivo central da diegese parece organizar-se em torno dessa personagem feminina, de suas fragmentadas lembranças, de sua solidão e de seu profundo amor por Ruby S., uma atriz de cinema de Hollywood com a qual ela possivelmente teria vivido, também se movimenta em torno da criação do texto que lemos.

Schlee parte de clichês recorrentes do universo prostibulário na configuração de sua protagonista - envelhecimento precoce, profunda solidão, miséria e degradação social e, inclusive, o do papel da caftina nos cuidados, complacente e severo, com "suas meninas". Se tais tópicos poderiam levar a um estereótipo da personagem Sara, ele acrescenta o da pedofilia, da prostituição infantil e da relação afetiva homossexual entre mulheres, bem como o da rejeição ao casamento como um direito pleno à sexualidade feminina, fazendo emergir assim uma personagem muito mais complexa. Talvez essa "saturação" de motivos no argumento textual seja a principal razão pela qual o narrador, em um exercício metaficcional, relacione o seu texto a um "modesto libreto de uma inédita opereta da Broadway ou um velho filme proibido pela lei de decência de Hollywood". (SCHLEE, 2013, p. 41)

Situando sua personagem Sara como uma puta de uma história irreal, proprietária de uma pensão de mulheres na periferia da cidade de Jaguarão, uma alcoólatra, que confunde as três meninas de seu reduzido plantel com o grande amor de sua vida, o narrador indica outro núcleo cuja referência passa a ser a atriz. Recorrendo a estratégias discursivas como "dizem que", "parece que", "Soube-se que" e até regressando no tempo para enfrentar a falta de memória de sua personagem, também o narrador entre suas reminiscências, a dos outros e sua imaginação criadora, refaz um possível mapa de circulação e atuação das duas mulheres. Sara, em seu circuito da Rússia para Havre/França para Buenos Aires para São Francisco para Nova Iorque para Buenos Aires para Nova Orleans e novamente para Buenos Aires até o dia em que, em fuga, é endereçada "a um tal Tomazito, Tomazino, Tomazinho", em Jaguarão (SCHLEE, 2013, p. 45), quando ainda estava por volta de seus vinte anos.

Já a personagem Ruby corporifica-se a partir da citação de títulos de filmes, de nomes de diretores e produtores cinematográficos, de 

na obra de Aldyr Garcia Schlee | 83

amigos e amores - reais ou imaginados - todos aparentemente por fragmentos de memória de nossa Sara e/ou da imaginação do narradorautor.

Ela só fez um filme mudo - diria a polaca Sara, se soubesse, diante de uma presumível fotografia de Ruby, num longo vestido de cetim branco, sob os dizeres de ILLICIT 1931. O filme mudo poderia ser Noches da Broadway, de 1972 ? Illicit terá sido Mulher sem Algemas (ou melhor: Mujer sin esposas?) (SCHLEE, 2013, p. 49).

É assim que Ruby S. - ou Ruby Stevens -, sabem os cinéfilos - e descobrem também os leitores atentos - é o nome original da atriz norteamericana Barbara Stanwyck. Ela, tal qual a nossa personagem Ruby S., estreou como dançarina em um filme mudo, Noites da Broadway, em $1927^{21}$ e fez destacada carreira no cinema. Entrecruzando dados da biografia de Ruby S. com os de Stanwyck ${ }^{22}$, tais como seu nascimento em 16 de junho de 1907, o itinerário de sua circulação por países e cidades, a infância órfã, o trabalho junto com a irmã como dançarina em casas de espetáculos, bares, cabarés ou como instrutora de dança em um bar para gays e lésbicas em Nova Iorque dos anos vinte, e títulos de filmes em que a atriz atuou, bem como de nomes de outros artistas citados e com quem ela contracenou ao longo de sua carreira na Broadway, o narrador imagina - e nós leitores também - a relação entre as duas personagens: S.R. ou "R.S.", sugerida desde o título do conto. Um espelhamento cujos fragmentos dispersos precisam ser aproximados pelo leitor em seu processo interpretativo. Afinal, ambas nasceram no mesmo dia, foram iniciadas sexualmente por volta dos dez anos de idade - uma, pelo padrasto; a outra, por um cunhado -, fizeram o possível para sobreviver e conheceram-se na juventude, nos Estados Unidos, conforme reiteradamente balbucia alcoolizada Sara, antes que ela fosse trazida para Buenos Aires e se perdesse de seu grande amor, Ruby/Stanwyck. Antes

${ }^{21}$ Broadway Nights é um filme norte-americano, mudo, que estreou em 1927, dirigido por Joseph C. Boyle. O filme teve como protagonistas Lois Wilson e Sam Hardy, e as estreantes Barbara Stanwyck e Ann Sothem como dançarinas.

22 Disponível em: <http://thehairpin.com/2013/03/scandals-of-classichollywood-the-many-faces-of-barbara-stanwyck/>. 


\section{4 | Cátia Dias Goulart}

que suas vidas tomassem rumos tão distintos quando, por muito tempo, estivessem estado tão próximos. Antes que Sara seguisse enredada nos mesmos caminhos que a iniciaram e Ruby conquistasse - tecendo na mesma teia, mas com outro fio, sua relativa autonomia - sexual, financeira e de identidades - reinventando-se com o ingresso no mundo da arte teatral e cinematográfica.

Como havia advertido o narrador desde o início, "Nem todas as histórias da vida difícil são como esta, aparentemente tão falsa" (SCHLEE, 2013, p. 41). Frente à ambiguidade provocativa do enunciado, cabe a pergunta: a vida de tal personagem Ruby Stevens/Stanwyck, é a de Sara ou a do narrador-autor em sua performance criativa? Assim, com duas ou várias histórias que se entrecruzam, nos meandros da memória trabalhada pelo processo criativo, diversas possibilidades de leitura são potencializadas. E eu assumo, para finalizar, apenas alguns fios do conto que me possibilitam significar caminhos abertos pela obra de Schlee e por esse viés mobilizar, também com eventuais leitores, um diálogo acerca da obra desse escritor.

Pensar em Sara, retomar a partir do enunciado seu trânsito entre países, seu longo percurso por esses quarenta anos no universo da prostituição é também pensar em Ruby S. / Barbara Stanwyck. E com essa associação o jogo criativo nos mobiliza a considerar também a vida de outras tantas artistas que, a exemplo das duas, tiveram as mesmas alternativas, como Sara Bernhardt, Edith Piaf, Joan Crawford ${ }^{23}$ bem como de tantas outras mulheres que ao ingressarem no mundo da arte tiveram que lidar com o estigma da prostituição. Mas que, como Ruby Stevens, e diferentemente da "nossa Sara", conseguiram lidar com suas alternativas para ultrapassar o limiar da miséria, tornando-se admiradas por suas performances como atrizes, cantoras e por todo um imaginário que criaram em torno de si, reinventando-se. Ainda que, talvez, elas também, em seus enfrentamentos, tenham se sentido em suas apostas de vida tão sós quanto "a nossa Sara".

23 Em especial, se atentarmos para biografias de atrizes como Sara Bernhardt, Edith Piaf ou Joan Crawford, encontraremos, tal como nas vidas de Ruby S. relações entre aliciamento, precocidade sexual e prostituição. Recomento as biografias: BERNHARDT, S. Eu, Sarah Bernhardt. Tradução Gilnara Lobato de Morais. José Olympio, 1ª. ed. [1949], 1988; BUQUE, C. Piaf, uma vida. Tradução Cecília Gianetti, São Paulo: LeYa Brasil, 2011. 

na obra de Aldyr Garcia Schlee | 85

Evidente que esse caminho de leitura brevemente abordado neste artigo demanda aprofundamento, questão que tenho procurado assumir em outros trabalhos, porque aqui, para finalizar, levo o rumo de minha prosa por outra linha, talvez um pouco para alinhavar as ligações sugeridas pelas várias histórias do aparente libreto de opereta anunciada no início do conto, mas, especialmente para retomar minha aspiração anunciada no título desse artigo.

Por isso, novamente chamo atenção para a performance autoral, marcada pela memória da personagem que cria, e das personagens as quais se refere, recriando-as e recriando-se nessa relação. Afinal, o narrador, personagem autoral, dissemina na diegese não só dados históricos acerca de uma região cultural e de um tempo específico, mas também dados que sugerem ao leitor experiências vitais do escritor da obra que lemos. Dentre tais referências que os aproximam - narradorautor e escritor - cabe destacar as imersões no campo da arte, não só pelo caráter metaficcional assumido no processo de criação, mas, sobretudo, pela fecunda sugestão de um repertório cinematográfico integrado à diegese ${ }^{24}$.

Essas são estratégias que mobilizam o leitor a considerar na obra de Aldyr Garcia Schlee os desdobramentos da memória, enquanto lembranças, esquecimentos e imaginação criadora. Afinal, se em sua obra Fitas de cinema (2015) ele se dedica integralmente a compor um repertório de leituras criativas de filmes clássicos, em Contos da vida difícil, não só pelo texto "Sedotta e abbandonata", conforme anunciei antes, mas também no conto aqui tratado, o escritor lida com relações entre filmes, suas memórias afetivas e histórias obliteradas em sua região cultural.

Assim, como podemos ver, Schlee não se limita a representar um território em suas criações, mas antes mobiliza seus leitores, a partir de diversas estratégias criativas, a pensarem a relação entre espaço, história, memória e a construção que dele fazemos.

${ }^{24}$ No conjunto da obra de Schlee, como mencionei anteriormente, há inúmeros contos que se referem a filmes que circulavam ou poderiam ter circulado nos cinemas de Jaguarão, Rio Branco e Pelotas. Dentre algumas narrativas que contribuem para a construção de uma experiência criativa a partir de um repertório fílmico no território literário criado pelo escritor, além dos já destacados, há "Missa por Rolando Vergara", "A última viagem" e "Os guris do Ipa", de Contos de verdades. 


\section{6 | Cátia Dias Goulart}

Nesses processos criativos, e profundamente éticos, descolonizar nossas memórias é, sobretudo, sair de uma dissimulada e pretensa neutralidade da relação espaço-representação e, a partir de uma perspectiva situada - como sugerido também por Torres Garcia - mobilizar a atenção do leitor tanto para as múltiplas experiências locais da ficção quanto para as inter-relações dessas experiências com o mundo em que se vive.

\section{REFERÊNCIAS}

KALIMAN, R. J. La palabra que produce regiones: el concepto de región desde la teoría literaria. Universidad Nacional de Tucumán. Facultad de Filosofía y Letras. Instituto de Historia y Pensamiento Argentinos. Programa Tucumán en el contexto de los Andes Centromeridionales. Documento de trabajo n. 3, julio, 1994. p. 1-23.

MIGNOLO, W. El occidentalismo y La 'americanidad' de América. In: . La Idea de América Latina - la herida colonial y la opción decolonial. Barcelona: Gedisa, 2007.

PALERMO, Z. El constructo región literaria: problemas y perspectivas. Congresso ABRALIC, 4, ANAIS. pp. 1093 -1110, 1994.

PIOVESAN, F. Direitos Humanos e o Direito Constitucional Internacional. 3ed. atual. São Paulo: Max Limonad. 1997.

RICOEUR, P. Tempo e narrativa (tomo. I). Tradução: Constança Marcondes Cesar. Campinas: Papirus, 1990.

RICOEUR, P. A memória, a história, o esquecimento. Tradução: Alain François [et al.]. Campinas: UNICAMPI, 2007.

RICOEUR, P. Del texto a la acción. Ensayos de hermenêutica II. Buenos Aires: Fondo de Cultura Econômica de Argentina, 2002.

RICOEUR, P. Teoria da Interpretação - o discurso e o excesso de significação. Tradução Artur Morão. Lisboa: Edições 70, 1996.

SAER, J. J. El concepto de ficción. In: . El concepto de Ficción.

Buenos Aires: Seix Barral, 2012.

SCHLEE, A. G. Fitas de cinema. Porto Alegre: Ar do tempo, 2015.

SCHLEE, A. G. Contos da vida difíiil. Porto Alegre: Ar do Tempo, 2013.

SCHLEE, A. G. Contos de sempre. Porto Alegre: Mercado Aberto, 1988.

SCHLEE, A. G. Linha divisória. São Paulo: Melhoramentos, 1988.

SCHLEE, A. G. Uma terra só. São Paulo: Melhoramentos, 1984. 
Performance autoral e imaginário de um território literário na obra de Aldyr Garcia Schlee | 87

Recebido em: 22/08/2019

Aceito em: 14/09/2019 